\title{
ORIGINAL
}

\section{A case of Cushing's syndrome due to bilateral cortisol- secreting adenomas with unilateral DHEAS oversecretion}

\author{
Satoshi Monno ${ }^{1)}$, Takamitsu Tachikawa ${ }^{2)}$, Takashi Maekawa ${ }^{3)}$ and Hironobu Sasano ${ }^{3)}$ \\ 1) Department of Medicine, Chiba-Nishi General Hospital, Matsudo, Japan \\ 2) Department of Urology, Chiba-Nishi General Hospital, Matsudo, Japan \\ 3) Department of Pathology, Tohoku University Graduate School of Medicine, Sendai, Japan
}

\begin{abstract}
A 39-year-old Japanese woman presented with typical clinical symptoms of Cushing's syndrome, including amenorrhea and hirsutism, for 2 years. The results of her initial endocrine evaluation were consistent with ACTHindependent Cushing's syndrome due to bilateral adrenal masses (diameter of $3.1 \mathrm{~cm}$ and $2.4 \mathrm{~cm}$ on the left and right, respectively). Serum dehydroepiandrosterone levels were $6,901 \mathrm{ng} / \mathrm{mL}$ (normal range 230-2,660 ng/mL). Bilateral laparoscopic adrenalectomies were performed (left adrenalectomy first and right adrenalectomy 3 months later). Following the left adrenalectomy, the results of the endocrine evaluations were still consistent with a diagnosis of ACTH-independent Cushing's syndrome. Serum dehydroepiandrosterone sulphate levels, however, were below the normal range (143 ng/mL). Unexpectedly, the patient's menstruation resumed 2.5 months after the left adrenalectomy. Pathological examination of the resected glands showed bilateral adrenocortical adenomas, one on the left with a diameter of $3 \mathrm{~cm}$, and two on the right with diameters of $0.7 \mathrm{~cm}$ and $1.3 \mathrm{~cm}$. Immunohistochemical analysis revealed side chain cleavage, $17 \alpha$-hydroxylase, $3 \beta$-hydroxysteroid dehydrogenase, and 21-hydroxylase immunoreactivity in each adenoma. Dehydroepiandrosteronesulfotransferase immunoreactivity was pronounced in the left adenoma, less pronounced in one of the right adenoma and weak in the other right adenoma. These results were consistent with clinical endocrine findings. Ours is the first case of a patient with bilateral cortisol-secreting adenomas with unilateral oversecretion of dehydroepiandrosterone sulphate. Resumption of menstruation after the correction of the dehydroepiandrosterone-sulphate excess, despite persistent cortisol excess, indicates the importance of adrenal androgens for the regulation of the menstrual cycle.
\end{abstract}

Keywords: Cushing's syndrome, Dehydroepiandrosterone sulphate, Dehydroepiandrosterone sulfotransferase, Cytochrome P450

CORTISOL-SECRETING adrenal adenomas account for $10-15 \%$ of endogenous Cushing's syndrome (CS) cases [1]. Bilateral cortisol-secreting adenomas, however, are extremely rare [2-6]. In contrast to ACTHdependent CS and adrenocortical-carcinomas, adrenocortical adenomas generally (with rare exception [7]) only secrete glucocorticoids without co-secretion of adrenal androgens [8]. We herein report a rare case of CS due to bilateral cortisol-secreting adrenal adenomas (one on the left and two on the right) with unilateral (left-sided) dehydroepiandrosterone sulphate (DHEAS) oversecretion. This is a unique hormonal

Submitted Nov. 19, 2014; Accepted Dec. 24, 2014 as EJ14-0552 Released online in J-STAGE as advance publication Jan. 21, 2015

Correspondence to: Satoshi Monno, M.D., PhD., Department of Medicine, Chiba-Nishi General Hospital, 107-1 Kanegasaku, Matsudo, Japan E-mail: frontsmonno@yahoo.co.jp

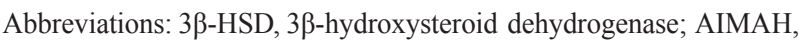
$\mathrm{ACTH}$-independent macronodular adrenal hyperplasia; BP, blood presentation of CS. To the best of our knowledge, the combination of these features has never been reported in the literature.

\section{Case Report}

A 39-year-old single woman presented to our endocrine clinic in September 2013 because of amenorrhea for 2 years, hirsutism including male-type excess body hair and hair thinning on the scalp, central obesity, moon-shaped face, and facial plethora. Her past medical history was significant for hypertension for 4 pressure; CS, Cushing's syndrome; CYP11B1, 11 $\beta$-hydroxylase; CYP11B2 (=P450aldo), aldosterone synthase; DHEAS, dehydroepiandrosterone sulphate; DHEA-ST, dehydroepiandrosterone sulfotransferase; LI, labeling index; P450c17, 17 $\alpha$-hydroxylase/ 17,20 lyase; P450scc, side chain cleavage enzyme; ZF, zona fasciculate; $\mathrm{ZG}$, zona glomerulosa; $\mathrm{ZR}$, zona reticularis 
years, for which she had been prescribed $20 \mathrm{mg}$ nifedipine twice daily, $50 \mathrm{mg}$ spironolactone once daily, and $40 \mathrm{mg}$ furosemide once daily by her primary care physician. On physical examination, she had a blood pressure (BP) of 129/90 mmHg. Her height was $160 \mathrm{~cm}$, she weighed $65 \mathrm{Kg}$, and her body mass index was 25.4. She had a round plethoric face, thin scalp hair, central adiposity, and increased dorsocervical and supraclavicular fat. Laboratory studies revealed an elevated random cortisol concentration and undetectable ACTH levels. The patient's 24-hour urine-free cortisol level was elevated at $469 \mu \mathrm{g} /$ day (normal $<90 \mu \mathrm{g} /$ day). Low-dose dexamethasone (1mg) failed to suppress serum cortisol. Serum DHEAS levels were elevated at $6,901 \mathrm{ng} /$ $\mathrm{mL}$ (normal $230-2,360 \mathrm{ng} / \mathrm{mL}$ ). Renin-angiotensinaldosterone system was not evaluated because of spironolactone treatment. Computed tomography of the abdomen demonstrated masses of $3.1 \mathrm{~cm}$ and $2.4 \mathrm{~cm}$ on the left and right adrenal glands, respectively (Fig. 1). ${ }^{131}$ I-6 $\beta$-iodomethyl-19-norcholesterol scintigraphy demonstrated bilateral adrenal uptake with greater intensity in the left adrenal gland (Fig. 2). Adrenal vein sampling was unsuccessful because the blood sample obtained from the right adrenal vein was not sufficient to evaluate DHEA levels (data not shown).

\section{Clinical course}

Bilateral laparoscopic adrenalectomies were performed on the patient (left adrenalectomy first, and right adrenalectomy 3 months later) Following the left adrenalectomy, the results of the endocrine evaluation revealed an abnormal low-dose dexamethasone suppression test, an elevated midnight serum cortisol concentration, and undetectable ACTH levels (Table 1). These findings were again consistent with a diagnosis of ACTH-independent Cushing's syndrome. After the

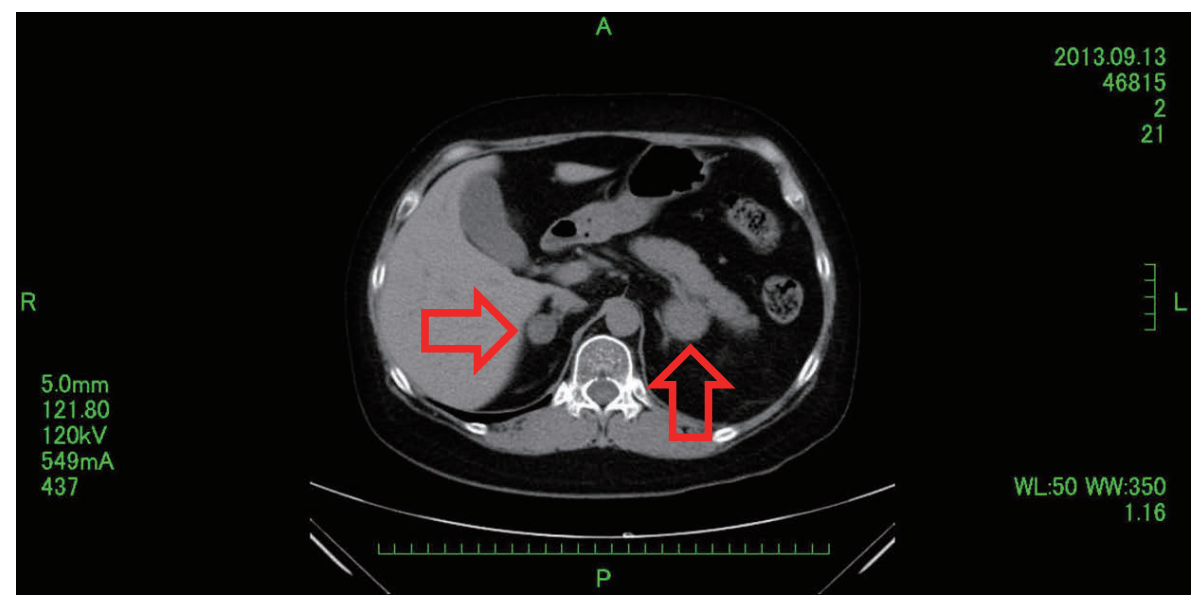

Fig. 1 A computed tomography image shows left and right adrenal masses (arrows) measuring $3.1 \mathrm{~cm}$ and $2.4 \mathrm{~cm}$ in diameter, respectively

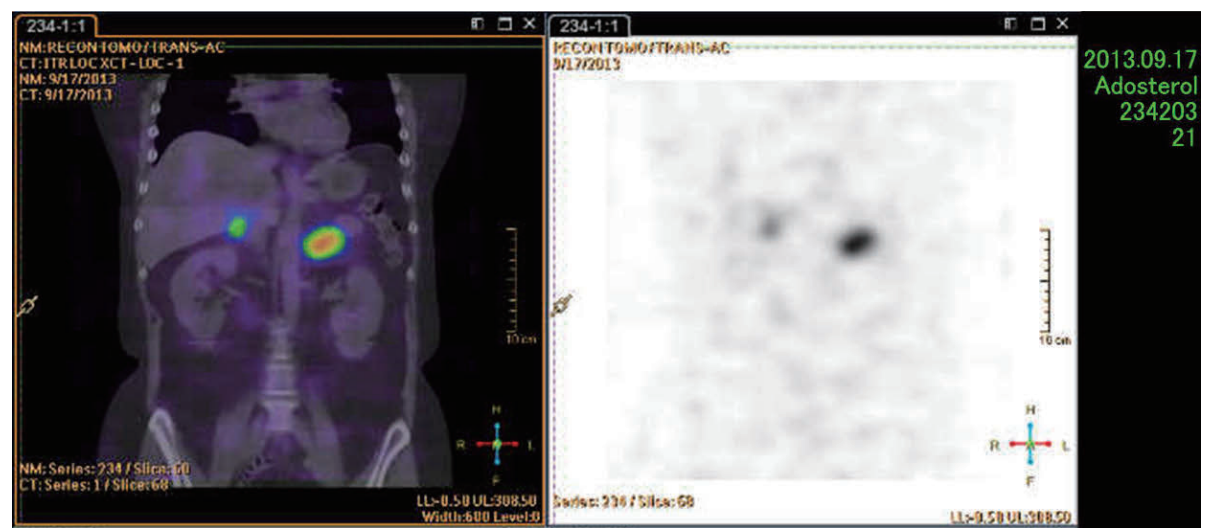

Fig. 2 A ${ }^{131}$ I-6 $\beta$-iodomethyl-19-norcholesterol scintigraphy showing bilateral adrenal uptake that was more pronounced on the left than on the right side 
Table 1 Hormone values

\begin{tabular}{|l|c|c|c|} 
& September 2013 & $\begin{array}{c}\text { November 2013 } \\
\text { After left adrenalectomy }\end{array}$ & $\begin{array}{c}\text { January 2014 } \\
\text { After right adrenalectomy }\end{array}$ \\
\hline $\begin{array}{l}\text { Cortisol }(\mu \mathrm{g} / \mathrm{dL}) \\
\text { AM }\end{array}$ & 19.6 & 13.1 & undetectable \\
$\begin{array}{l}\text { Midnight } \\
24 \mathrm{hr} \text { urine }(\mu \mathrm{g} / \text { day) } \\
(\text { normal }<90 \mu \mathrm{g} / \text { day) }\end{array}$ & 18.9 & 10.5 & \\
\hline $\begin{array}{l}\text { 1mg Dexamethasone } \\
\text { suppression test: }\end{array}$ & 469 & 114.8 & Not done \\
$\begin{array}{l}\text { Cortisol }(\mu \mathrm{g} / \mathrm{dL}) \\
\text { (normal }<1.8 \mu \mathrm{g} / \mathrm{dL})\end{array}$ & 30.2 & 11 & Not measured \\
\hline $\begin{array}{l}\text { DHEAS }(\mathrm{ng} / \mathrm{mL}) \\
(\text { normal } 230-2660 \mathrm{ng} / \mathrm{mL})\end{array}$ & 6901 & 143 & \\
\hline
\end{tabular}
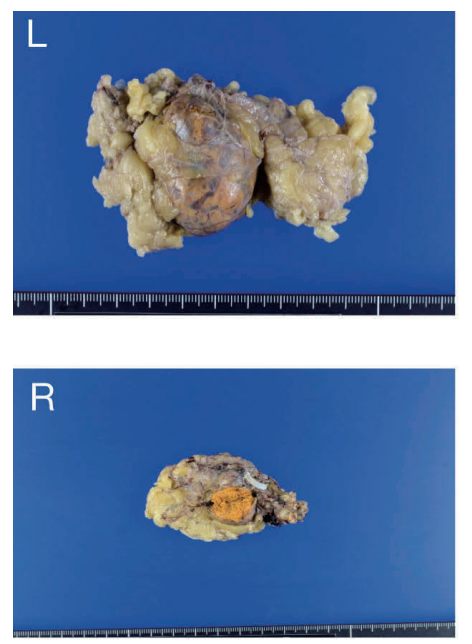
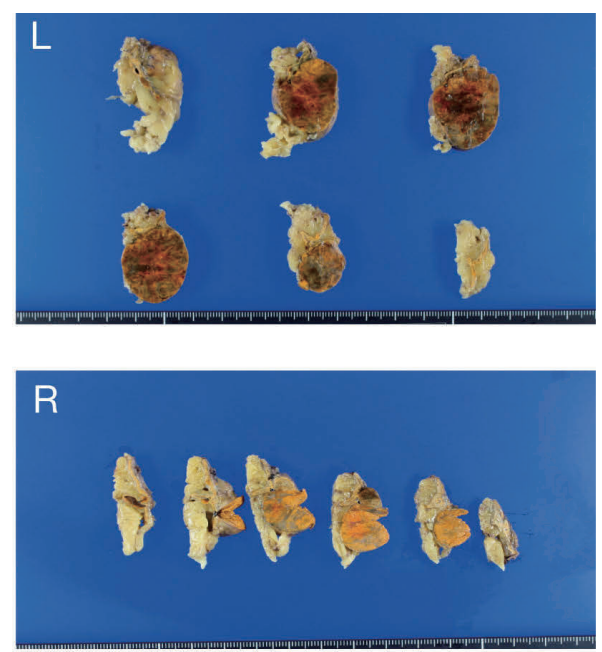

Fig. 3A Macroscopic views and cut surfaces of the resected adrenal masses show $3 \mathrm{~cm}$ left-sided adrenal adenoma with golden colored cut surfaces, and $0.7 \mathrm{~cm}$ and $1.3 \mathrm{~cm}$ right-sided adenomas with yellow-colored cut surfaces

left adrenalectomy, the patient's serum DHEAS concentration was $143 \mathrm{ng} / \mathrm{mL}$, which is below the normal range. Unexpectedly, her menstruation resumed 2.5 months after the left adrenalectomy. Her BP had been controlled around $120-130 / 80-90 \mathrm{mmHg}$ by calcium channel blocker (amlodipine $10 \mathrm{mg}$ once a day). Three months after the first surgery, she underwent the right adrenalectomy, and was put on hydrocortisone and fludrocortisone replacement therapy. Her BP improved after surgery, and as a consequence, her BP medications were discontinued. The patient's menstruation stayed in regular cycle of 25 days interval after the bilateral adrenalectomies.

\section{Immunohistochemical analysis}

Bilateral adenomas were tested for various antigens using immunohistochemical methods described previously $[9,10]$. Analysis of steroidogenic enzymes was performed for both adrenal glands. P450 side chain cleavage (scc; also termed cholesterol side chain cleavage enzyme [CYP11A]), P450c17 (also termed $17 \alpha$-hydroxylase/ 17,20 lyase [CYPc17]), 3 $\beta$-hydroxysteroid dehydrogenase (3ß-HSD), P450c11 (also termed 11 $\beta$-hydroxylase [CYP11B1], P450aldo (also termed aldosterone synthase [CYP11B2]) and dehydroepiandrosterone sulfotransferase (DHEA-ST) were analyzed in this study. Ki67 was also evaluated, and the Ki67 labeling index (LI) was obtained.

\section{Histopathological analysis}

Pathological examination of the resected adrenal glands demonstrated bilateral adrenocortical adenomas (one on the left with a diameter of $3.1 \mathrm{~cm}$, and two on the right with diameters of $0.7 \mathrm{~cm}$ and $1.3 \mathrm{~cm}$ ) with adjacent atrophied zona fasciculata (ZF) and zona reticularis (ZR) (Fig. 3A). The cut surface of 
the adenomas appeared yellow to golden color. These three lesions were diagnosed as adrenocortical adenomas according to the Weiss score [11]. They were mainly composed of eosinophilic compact cells, with a pronounced immunoreactivity of P450scc, 3 $\beta$-HSD, $\mathrm{P} 450 \mathrm{c} 17$, and $\mathrm{P} 450 \mathrm{c} 11$, indicating their ability to synthesize glucocorticoids and androgens (Fig. 3B). In the left adenoma, DHEA-ST-positive dysmorphic cells with abundant eosinophilic cytoplasm were predominant, whereas the two adenomas of the right adrenal gland were mainly composed of compact cells with relatively weak DHEA-ST immunoreactivity in one adenoma and compact cells intermingled with clear cells with weak to moderate DHEA-ST immunoreactivity in the other (Fig. 3B). P450aldo, which is exclusively expressed in the zona glomerulosa $(\mathrm{ZG})$ but not the $\mathrm{ZF}$ or ZR of the normal adrenal cortex, was only detected in the right adenomas, suggesting that aldosterone was produced only in right adenomas (Fig. 3B). The Ki67 LI was higher in the left adenoma (2.5\%) than the right adenomas $(1.5 \%)$ but in the known range for adrenocortical adenomas for both sides. These results indicate a more pronounced cell proliferation and DHEAS production in the left adenoma compared to the right adenomas, consistent with clinical endocrine findings. The findings also reinforced the importance of immunohistochemical analysis of steroidogenic enzymes in clinical specimens in order to explore a pathological-endocrine correlation.

\section{Discussion}

To the best of our knowledge, this is the first report of CS due to bilateral cortisol-secreting adenomas with unilateral oversecretion of DHEAS. Bilateral cortisol-secreting adenomas are a rare cause of CS, a condition that is predominantly seen in women of child-bearing age [2-6] as was the case in our patient. Making a differential diagnosis between cortisol-secreting adenomas and ACTH-independent macronodular adrenal hyperplasia (AIMAH) or unilateral cortisol-secreting adenoma with a contralateral nonfunctioning cortical adenoma is a challenge [12]. ${ }^{131} \mathrm{I}-6 \beta$-iodomethyl-19norcholesterol scintigraphy was used to rule out the latter diagnosis. Most patients with overt CS due to AIMAH present in their 50s or 60s [13], which is a later age of onset compared to patients with cortisol-producing adenomas. Findings characteristic for AIMAH include bilateral cortical masses that are multinodular and amplified contours of the adrenal glands on imaging [14]. Such masses were not found in our patient. However, a clear distinction from AIMAH could not be made until the pathological evaluation of the resected glands had been performed. Adrenal vein sampling, which is a technically demanding and invasive procedure has been reported to be useful for the differential diagnosis of CS with bilateral adrenal masses [15]. However, we could not obtain sufficient blood samples for this procedure.

Adrenal adenomas generally (with rare exception [7]) only secrete glucocorticoids. In contrast, androgen excess usually occurs in women with adrenal cancer or ACTH-stimulated hyperandrogenism [8]. In our patient, however, serum DHEAS levels were very high before surgery and below the normal range after her left adrenalectomy. Adrenal cancer was ruled out by using the Weiss score. Immunohistochemical analysis of the resected adrenal adenomas revealed pronounced expression of P450scc, 3 $\beta$-HSD, P450c17, and $\mathrm{P} 450 \mathrm{c} 11$. These are enzymes implicated in glucocorticoid and androgen production in the normal $\mathrm{ZF}$ and $\mathrm{ZR}$, suggesting overproduction of cortisol and androgens (mainly $\Delta 5$ pathway and DHEA) in the bilateral adenomas. Immunoreactivity of DHEA-ST, an enzyme expressed in the normal ZF and ZR, was more pronounced in the left adenoma than the right adenomas, implying higher DHEAS production in the left adenoma than the right adenomas, a finding consistent with clinical endocrine data. Interestingly, P450aldo, an enzyme expressed only in normal ZG but not in the $\mathrm{ZF}$ or ZR, was observed in the right adenomas, suggesting aberrant expression of CYP11B2 in these adenoma cells. We could not assess the renin-angiotensin-aldosterone system before the adrenalectomies were performed because the patient had been treated with spironolactone.

Menstrual irregularities are common in women with CS [8]. Increased cortisol and decreased serum estradiol but not serum androgen concentrations are believed to be associated with menstrual abnormalities [8]. Suppression of secretion of gonadotropin-releasing hormone by hypercortisolemia has been hypothesized to be the cause of these menstrual irregularities [16]. In our patient, however, menstruation resumed concomitant with a reduction in serum DHEAS levels after the left adrenalectomy and despite continuous autonomous cortisol secretion from the right adrenal adenomas. While substantial reduction of cortisol 
Light microscopic findings of the left

Magnifying-glass-view of a part of the adenoma, mainly composed of left adrenal adenoma with atrophied dysmorphic compact cells with normal gland
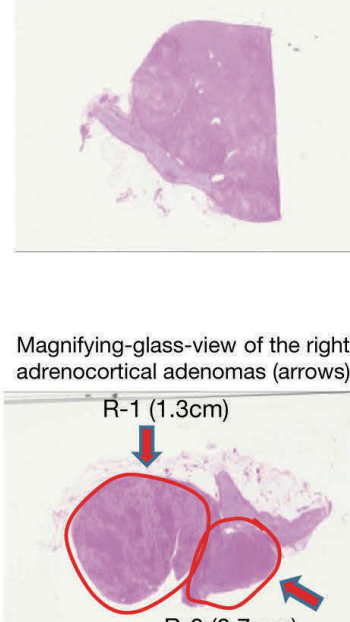

$\mathrm{R}-2(0.7 \mathrm{~cm})$

dysmorphic compact cells with

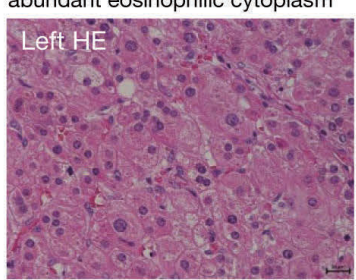

Light microscopic findings of the right adenomas

$\mathrm{R}-1$ : compact cells intermingled by clear cells

R-2: mainly compact cells

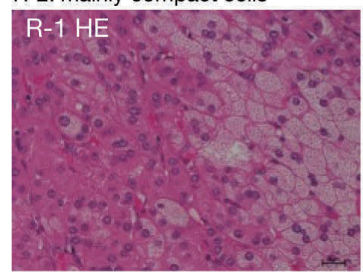

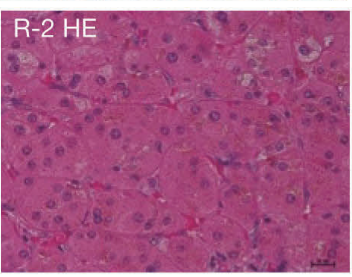

CYP11A(P450scc)
in the left adenoma

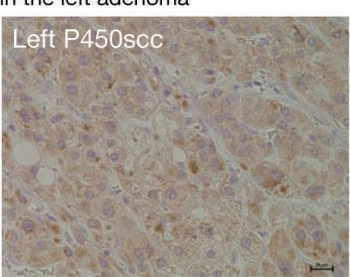

CYP11A(P450scc) immunoreactivity 33HSD immunoreactivity in the right adenomas
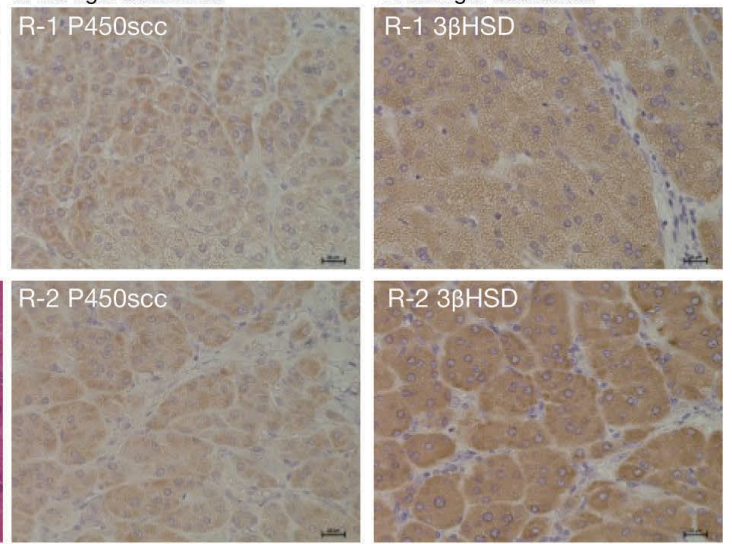

CYPc17 (P450c17) immunoreactivity

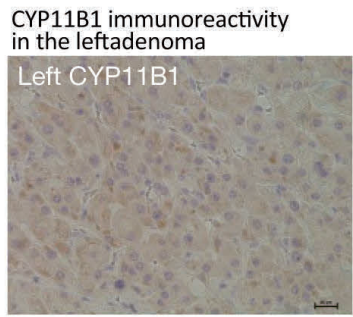

CYP11B1 imm
adenomas
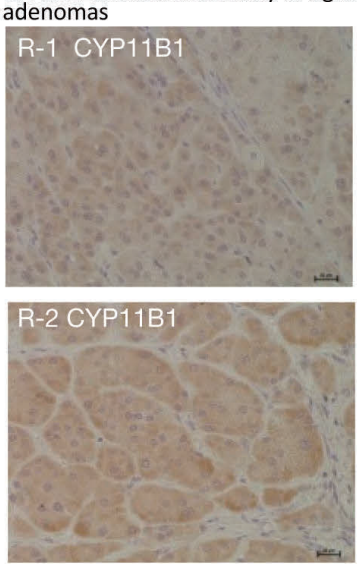

CYP11B2 negative in the left adenoma

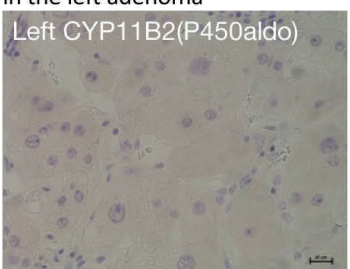

DHEA-ST immunoreactivity in the left adenoma

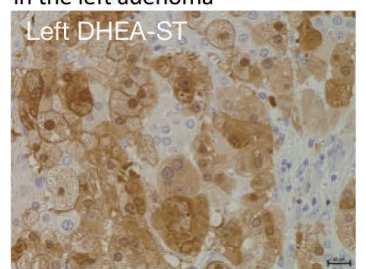

DHEA-ST immunoreactivity in the right adenomas weak in R-1 and weak to moderate in R-2
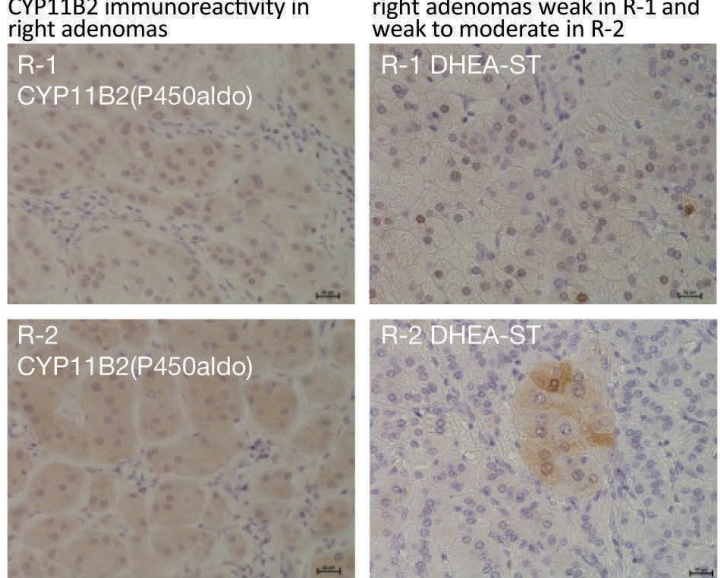

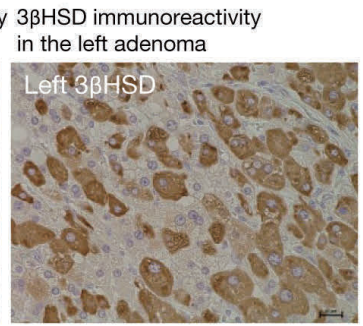
in the right adenomas

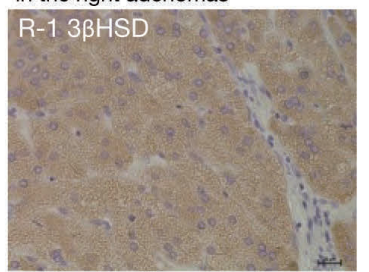
in the right adenomas
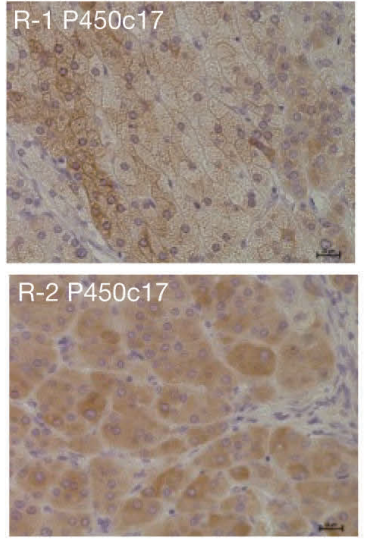

CYPc17 (P450c17) immunoreactivity in the left adenoma

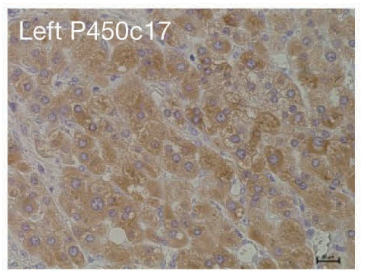

Ki67 labeling index was 2.5\% in the left adenoma

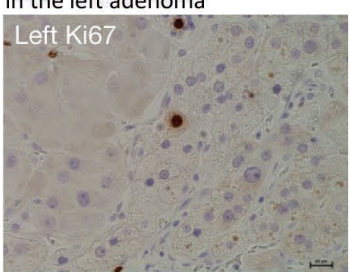

Ki67 labeling index was 1.5\% in the right adenomas
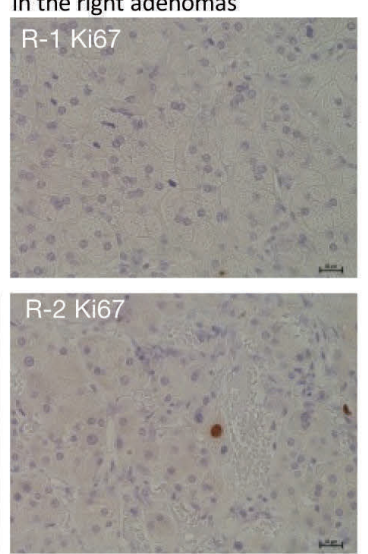

Fig.3B Magnifying-glass-views of the resected adrenal masses and immunohistochemical staining (hematoxylin and eosin [H\&E] staining and immunostaining with magnification of $\times 400$ : bars denote $20 \mu \mathrm{m}$ ) of steroidogenic enzymes expressed in the left and right adenomas. Expression profiles of the enzymes in the left adrenal adenoma and in the $1.3 \mathrm{~cm}$ right (R-1) and $0.9 \mathrm{~cm}$ right adenoma (R-2) are depicted in the upper, middle, and lower panels, respectively.

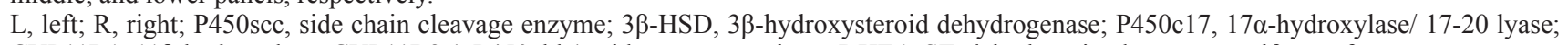
CYP11B1, 11ß-hydroxylase; CYP11B2 (=P450aldo), aldosterone synthase, DHEA-ST, dehydroepiandrosterone sulfotransferase 
secretion by the left adrenalectomy could be one of contributing factors, we believe these data suggest that normalizing adrenal androgen levels is crucial for the resumption of menstruation in women with CS.

\section{Discosure}

None of the authors have any potential conflicts of interest associated with this research.

\section{References}

1. Nieman L (2014) Establishing the cause of Cushing's syndrome. UpToDate Available at http://www.uptodate. com. Accessed June 11, 2014.

2. Aiba M, Kawakami M, Ito Y, Fujimoto Y, Suda T, et al. (1992) Bilateral adrenocortical adenomas causing Cushing's syndrome. Report of two cases with enzyme histochemical and ultrastructural studies and review of the literature. Arch Pathol Lab Med 116: 146-150.

3. Makino S, Chikazawa H, Yorimitsu A, Suehiro T, Hashimoto K, et al. (1997) A rare case of Cushing's syndrome due to bilateral adrenocortical adenomas. Endocr J 44: 533-540.

4. Nomura K, Saito H, Aiba M, Iihara M, Obara T, et al. (2003) Cushing's syndrome due to bilateral adrenocortical adenomas with unique histological features. Endocr J 50: 152-162.

5. Tung SC, Wang PW, Huang TL, Lee WC, Chen WJ (2004) Bilateral adrenocortical adenomas causing ACTH-independent Cushing's syndrome at different periods: a case report and discussion of corticosteroid replacement therapy following bilateral adrenalectomy. J Endocrinol Invest 27: 375-379.

6. Li Z, Zhu Y, Kong C, Yin L, Gao Z, et al. (2011) Corticotropin-independent Cushing's syndrome in patients with bilateral adrenal masses. Urology 77: 417421.

7. Fukushima A, Okada Y, Tanikawa T, Kawahara C, Misawa H, et al. (2003) Virilizing adrenocortical adenoma with Cushing's syndrome, thyroid papillary carcinoma and hypergastrinemia in a middle-aged woman. Endocr J 50: 179-187.

8. Nieman L (2014) Epidemiology and clinical manifestations of Cushing's syndrome. UpToDate Available at: http://www.uptodate.com. Accessed June 11, 2014.
9. Sasano H, Shizawa S, Suzuki T, Takayama K, Fukaya $\mathrm{T}$, et al. (1995) Transcription factor adrenal 4 binding protein as a marker of adrenocortical malignancy. Hum Pathol 26: 1154-1156.

10. Sasano H, Miyazaki S, Sawai T, Sasano N, Nagura H, et al. (1992) Primary pigmented nodular adrenocortical disease (PPNAD): immunohistochemical and in situ hybridization analysis of steroidogenic enzymes in eight cases. Mod Pathol 5: 23-29.

11. Weiss LM, Medeiros LJ, Vickery AL Jr (1989) Pathologic features of prognostic significance in adrenocortical carcinoma. Am J Surg Pathol 13: 202-206.

12. Maghrabi A, Yaqub A, Denning KL, BenHamed N, Faiz S, et al. (2013) Challenges in the diagnostic work-up and management of patients with subclinical Cushing's syndrome and bilateral adrenal masses. Endocr Practice 19: $515-521$.

13. Lacroix A (2014) Cushing's syndrome due to primary bilateral macronodular adrenal hyperplasia. UpToDate Available at http://www.uptodate.com. Accessed Dec 17, 2014.

14. Lacroix A (2009) ACTH-independent macronodular hyperplasia. Best Pract Res Clin Endocrinol Metab 23: 245-259.

15. Young WF Jr, du Plessis H, Thompson GB, Grant CS, Farley DR, et al. (2008) The clinical conundrum of corticotropin-independent autonoumous cortisol secretion in patients with bilateral adrenal masses. World J Surg 32: 856-862.

16. Penezić Z, Zarković M, Vujović S, Cirić J, Beleslin B, et al. (2005) Gonadotropin pulsality in Cushing's syndrome compared with polycystic ovary syndrome. Gynecol Endocrinol 20: 150-154. 